\title{
IDENTIFIKASI FAKTOR YANG MEMPENGARUHI SUKSES WIRAUSAHA
}

\author{
Edy Purwo Saputro ${ }^{1}$, Nur Achmad ${ }^{2}$, Sih Handayani ${ }^{3}$ \\ 1,2J1. A. Yani Tromol Pos 1 Pabelan, Kartasura, Sukoharjo, Central Java, Indonesia \\ e-mail : E.Purwo.Saputro@ums.ac.id,nur.achmad@ums.ac.id \\ ${ }^{3}$ AMIK Cipta Darma Surakarta \\ e-mail : epsums@1ycos.com
}

\begin{abstract}
Entrepreneurship is one of essential factors that contributing for economic development. The role of women entrepreneur is pivotal in this regard. This study examined factors that influencing the success of women's entrepreneur. This study used 231 respondents that located in Solo. The data gathered are analyzed by structural equation model. The result indicated that micro, macro, performance and capability positively influenced to the success of entrepreneur.
\end{abstract}

Keywords: women entrepreneur, success factors.

\section{PENDAHULUAN}

Perkembangan ekonomi global berpengaruh terhadap penumbuh kembangan etos kewirausahaan, yaitu tidak hanya di negara industri maju, tetapi juga di negara miskin berkembang. Hal ini karena keberhasilan dari penumbuhkembangan kewirausahaan itu sendiri akan memberikan manfaat makro, tidak hanya bagi negara, tapi juga bagi pelaku wirausaha itu sendiri (Sullivan dan Meek, 2012; Siringi, 2011). Alasan yang mendasari terkait dengan persoalan kesejahteraan, kemiskinan, pengangguran dan ketenagakerjaan karena supply sumber daya lebih besar dibanding kebutuhan tenaga kerja.

Komitmen terhadap penumbuh kembangan kewirausahaan tidak hanya mengacu kepada kepentingan jangka pendek, tapijuga mengacu kepentingan jangka panjang. Hal ini tidak hanya terkait dengan orientasi pembangunan dan pemberdayaan, tapi juga nilai penting terhadap geliat ekonomi rakyat. Oleh karena itu, mata rantai dari kewirausahaan sangat panjang dan karenanya kajian tentang kewirausahaan terus berkembang. Di satu sisi, hal ini memberikan kontribusi terhadap perkembangan teoritis dan empiris, dan di sisi lain identifikasi terhadap sukses faktor kewirausahaan itu sendiri menjadi semakin menarik dikaji (Short, et al., 2009).

Persoalan tentang sukses faktor wirausaha dipengaruhi oleh beberapa aspek dan hal ini mengindikasikan bahwa identifikasi persoalan kewirausahaan itu sendiri terkait dengan aspek mikro - makro atau internal - eksternal sehingga temuan dari setiap kasus yang ada cenderung menggambarkan argumentatif yang sesuai setting amatan. Terkait ini maka pemetaan sejumlah riset empiris tentang kewirausahaan menjadi acuan penting untuk bisa menjawab persoalan sukses faktor wirausaha (Sánchez dan Gutiérrez, 2011; Veciana dan Urbano, 2008; Ireland, et al., 2005).

Fakta dari keberagaman riset empiris tentang kewirausahaan dan pemetaan yang dilakukan sejumlah peneliti menegaskan bahwa tidak ada satupun modal yang mampu menjawab tantangan peningkatan kesejahteraan melalui kewirausahaan. Hal ini karena tujuan utama pelaku kewirausahaan adalah meningkatkan taraf kesejahteraan dirinya yang kemudian terkait mata rantainya dapat mempengaruhi taraf kesejahteraan lainnya. Terkait ini, Rauch dan Frese, (2000) menegaskan bahwa sukses faktor wirausaha dapat diidentifikasi melalui 5 faktor yaitu lingkungan, kepribadian, tujuan, human capital dan strategi. Meski demikian, temuan sejumlah peneliti menegaskan ada banyak faktor yang mempengaruhi sukses wirausahawan (Forson, 2013; Kumar, 2013; Kwong, et al., 2012; Dawson dan Henley, 2012; Pines, et al., 2010). Fakta ini kemudian menjadi argumen bagi Simpeh (2011) untuk menyebut bahwa perkembangan dari kewirausahaan tersebut 
mempengaruhi konsep dan teoritis dari kewirausahaan itu sendiri.

Temuan hasil riset empiris dan pemetaan riset tentang kewirausahaan menjadi acuan pentingnya kajian tentang kewirausahaan yang dilakukan oleh wanita. Argumen yang mendasari karena populasi wanita cenderung lebih besar dibanding dengan pria. Selain itu, aspek demografi juga mengindikasikan bahwa peran wanita dalam keluarga relatif lebih besar sehingga peran wanita dalam membantu keuangan rumah tangga saat ini menjadi isu yang menarik. Terkait hal ini, salah satu peran yang bisa dilakukan oleh wanita yaitu berwirausaha. Perkembangan internet smartphone secara tidak langsung menjadi faktor yang juga mendukung perkembangan wirausaha wanita, terutama untuk transaksi yang dilakukan online. Oleh karena itu, era e-commerce juga menjadi acuan pentingnya sukses faktor wirausaha wanita karena dukungan tarif internet yang semakin murah dan akses yang semakin mudah. Meski demikian, wirausaha model offline juga tidak bisa diabaikan kontribusinya terhadap ekonomi rumah tangga karena wanita yang berprinsip tradisional masih mengandalkan transaksi offline - tradisional. Hal ini secara tidak langsung menunjukan model transaksi online tidak sekaligus menggantikan model transaksi offline yang masih tradisional.

Penjabaran diatas mengindikasikan sukses faktor wirausaha secara umum dan khususnya bagi wanita menjadi isu yang menarik (Canizares dan Garcia, 2010). Meski demikian, temuan sejumlah riset empiris tentang sukses faktor wirausaha perlu menjadi perhatian, terutama dalam aspek pendalaman kasus sesuai setting amatan untuk setiap riset terkait kewirausahaan (Rao, et al., 2013; Vadnjal dan Vadnjal, 2013; Chong, 2012; Kargwell, 2012; Alam, et al., 2011; Pines, et al., 2010; Robichaud, et al., 2010; Zhu dan Chu, 2010; Jamali, 2009). Di satu sisi era global memberikan peluang wirausaha wanita untuk memacu kinerja ekonomi dan di sisi lain tantangan dan persaingan juga semakin ketat sehingga pelaku wirausaha wanita yang masih eksis menjadi menarik untuk dikaji.

\section{Rumusan Masalah}

Kajian tentang kewirausahaan seharusnya tidak mengacu bias jender, yaitu pria - wanita, namun aspek demografijustrumengidentifikasi perbedaan tersebut. Padahal, sukses faktor wirausaha wanita tidak hanya memberikan pengaruh terhadap prospek ke depan bagi perekonomian, tetapi juga eksistensi melalui pemberdayaan secara kontinu. Fakta ini yang kemudian menjadi argumen tentang urgensi riset kewirausahaan wanita, terutama mengacu mata rantai yang muncul (van Gelderen, et al., 2008). Oleh karena itu, rumusan masalah penelitian ini: bagaimana identifikasi sukses faktor wirausaha?

\section{Tujuan dan Manfaat Penelitian}

Keberagaman risettentang kewirausahaan memberikan gambaran yang penting tentang sukses faktor wirausaha. Oleh karena itu, tujuan penelitian ini adalah menguji sukses faktor kewirausahaan mengacu setting amatan pelaku wirausaha wanita di Solo. Di satu sisi, manfaat penelitian ini adalah memberikan pendalaman pemahaman sukses faktor wirausaha dari aspek praktis dan di sisi lain terkait aspek teoritis maka penelitian ini memberikan manfaat melalui pengembangan konsep - teoritis tentang sukses faktor wirausaha wanita. Selain itu, manfaat lainnya yaitu membangun stimulus terkait faktor yang mendukung sukses wirausaha. Pemerintah juga berkepentingan dengan manfaat dari penelitian ini melalui penciptaan regulasi yang mendukung sukses faktor wirausaha

\section{TINJAUAN PUSTAKA}

\section{Identifikasi Riset Kewirausahaan}

Perkembangan riset kewirausahaan yang dilakukan wanita dibedakan menjadi dua, pertama: mereka yang mencoba untuk berwirausaha lalu berhasil dan yang kedua: mereka yang sedari awal berniat berwirausaha sebagai konsekuensi tuntutan untuk bisa survive (Abu-Asbah dan Heilbrunn, 2011). Faktor pertama disebabkan karena tuntutan ekonomi keluarga sehingga peran wanita menjadi pendukung pendapatan suami, tetapi faktor yang kedua lebih mengacu faktor kondisi. Identifikasi untuk faktor yang kedua cenderung dialami oleh pendatang. Oleh karenanya itu, kasusnya lebih mengacu kepada daerah yang menjadi tujuan migrasi. Perbedaan faktor penyebab dari kedua kondisi 
ini juga mempengaruhi setting amatan setiap kasusnya.

Temuan kasus untuk faktor kedua cenderung lebih banyak terjadi di negara atau daerah dengan tingkat pertumbuhan ekonomi tinggi atau sentra ekonomi. Oleh karena itu pusat-pusat pemerintahan dan perekonomian menjadi daerah yang banyak terjadinya kasus tersebut. Hal ini kemudian memicu dikotomi antara pendatang vs penduduk asli di suatu daerah - negara. Fenomena ini rentan memicu kecemburuan sosial, terutama jika para pendatang lebih sukses secara ekonomi, termasuk juga konsekuensi semakin banyaknya pelaku wirausaha yang dilakukan oleh wanita pendatang. Terkait ini, maka beralasan jika Al-Dajani dan Marlow (2013) menegaskan sukses wirausaha di daerah perantauan memicu ancaman konflik sosial, apalagi jika yang minoritas cenderung bisa lebih sukses secara ekonomi dibanding warga asli.

Identifikasi dari kedua faktor diatas maka sukses faktor wirausaha wanita secara tidak langsung dipengaruhi oleh motivasi, baik dalam bentuk motivasi internal ataupun eksternal (Aramand, 2013; Forson, 2013; Dawson dan Henley, 2012; Canizares dan Garcia, 2010). Artinya untuk faktor yang pertama terkait dengan motivasi trial and error dengan mengacu aspek internal dan eksternalnya, sedangkan untuk faktor kedua terkait dengan motivasi untuk survive yang lebih disebabkan karena faktor marginal, misalnya karena kondisinya sebagai pendatang atau kelompok minoritas. Fakta tersebut memberi gambaran bahwa wirausaha wanita memiliki potensi dan kesempatan yang sama untuk bisa sukses. Oleh karena itu argumen Marlow dan McAdam (2013) tidak relevan karena fakta menunjukan bahwa wanita dan pria memiliki kesempatan yang sama untuk dapat bersaing di bidang kewirausahaan.

Pemahaman tentang motivasi sebagai faktor riil yang mendukung keberhasilan wirausaha wanita pada dasarnya juga terkait dengan faktor pendorong dan penarik yang muncul dari pelaku wirausaha (Dawson dan Henley, 2012). Artinya, pelaku wirausaha yang mampu mengidentifikasi faktor pendorong dan penarik sehingga memulai untuk berwirausaha maka mereka memiliki tahapan awal untuk sukses berwirausaha. Terkait hal ini, maka pelaku wirausaha yang tidak mampu mengimplementasikan semua faktor pendorong dan penarik tersebut maka pada dasarnya mereka telah gagal berwirausaha. Argumen yang mendasari karena pada dasarnya mereka yang mampu mengidentifikasi dan mengimplementasikannya maka secara tidak langsung mereka berhasil membuka peluang dan pasar baru (Gonzalez-Alvarez dan Solis-Rodriguez, 2011). Oleh karena itu, mengacu temuan kedua faktor diatas maka dapat disimpulkan bahwa kewirausahaan itu dapat diciptakan dan stimulus terhadap penciptaannya bisa dilakukan dengan faktor dari internal dan eksternal atau dengan faktor pendorong dan penarik sehingga sukses faktor wirausaha dapat dilakukan secara berkelanjutan. Jika penumbuhkembangan wirausaha ini bisa dilakukan berkelanjutan maka hal ini akan menjadi modal sosial yang baik bagi kebangkitan ekonomi domenstik (rumah tangga dan negara).

Pembahasan kedua faktor diatas memberikan peluang melakukan riset lanjutan tentang sukses faktor wirausaha wanita sesuai setting amatan. Arumen yang mendasari karena sukses faktor tersebut bukan hanya disebabkan motivasi (Hattab, 2012; Itani, et al., 2011) dan faktor dorongan atau push dan faktor yang menarik atau pull (Itani, et al., 2011), tetapi juga faktor efikasi diri, persepsi terhadap risiko, tradisi yang berkembang, budaya sosial dan negative stereotypes (Javadian dan Singh, 2012). Hal ini menguatkan argumen Sullivan dan Meek (2012) bahwa keberagaman sukses faktor wirausaha tidak bisa diabaikan sehingga dapat dipetakan setiap komponen yang mendukungnya.

\section{Faktor Pendukung}

Era otonomi daerah yang ditandai pemekaran daerah dan komitmen pemerintah terhadap pengembangan ekonomi kreatif pada dasarnya memberikan peluang terhadap penumbuhkembangan kewirausahaan, termasuk juga yang dilakukan oleh wanita. Oleh karena itu, basis-basis ekonomi kreatif di daerah dan juga potensi kewirausahaan harus banyak bermunculan. Jika hal ini berhasil maka akan dapat mereduksi dikotomi yang selama ini mereduksi potensi kewirausahaan dan sekaligus bisa meningkatkan ekonomi kesejahteraan (Aramand, 2013; Kyrgidou dan 
Petridou, 2013; Marlow dan McAdam, 2013; Pathak, et al., 2013; Javadian dan Singh, 2012; Patterson, et al., 2012; Gonzalez-Alvarez dan Solis-Rodriguez, 2011; Canizares dan Garcia, 2010).

Pemahaman tentang urgensi - komitmen penumbuhkembangan kewirausahaan, maka semua faktor yang mereduksi sukses faktor wirausaha harus dilakukan (Al-Dajani dan Marlow, 2013; Hattab, 2012; Abu-Asbah dan Heilbrunn, 2011; Itani, et al., 2011; Blackburn dan Kovalainen, 2009). Keberhasilan dalam penumbuhkembangan tersebut akan berpengaruh terhadap stimulus dan embrio wirausaha lainnya sehingga kajian dari sukses faktor tersebut tidak hanya memperkaya aspek teoritis - konseptual, tetapi juga relevansinya terhadap pengembangan regulasi tentang pemberdayaan wanita khususnya dan regulasi tentang kewirausahaan secara umum (HoyosRuperto, et al., 2013; Lee dan Yang, 2013; Zulkifli dan Rosli, 2013; Alam, et al., 2012).

Urgensi tentang regulasi kewirausahaan maka stimulus kewirausahaan bisa juga dikembangkan melalui jalur pendidikan formal dengan penciptaan kurikulum, terutama yang mampu bersinergi antara teori dan praktek. Oleh karena itu, beralasan jika Raposo dan do Paço (2011) menegaskan pentingnya edukasi sedari dini terkait kewirausahaan dan hal ini pada dasarnya bisa dibangun mulai dari jenjang pendidikan dasar, menengah dan di perguruan tinggi. Artinya sukses faktor wirausaha, termasuk yang dilakukan oleh wanita bisa diciptakan dengan berbagai model pendekatan stimulus dan edukasi, selain juga dipengaruhi oleh faktor-faktor diatas.

Implikasi jangka panjang sukses faktor wirausaha tidak hanya bagi kepentingan ekonomi rumah tangga, tetapi juga kesejahteraan nasional sehingga mampu mereduksi pengangguran dan kemiskinan. Sinergi kepentingan jangka pendek dan panjang sukses wirausaha mengindikasikan bahwa pemetaan semua faktor yang mempengaruhi sukses wirausaha adalah sangat penting. Meskipun setting amatan juga berpengaruh terhadap generalisasi hasil, tapi pemetaan menjadi acuan terhadap sukses faktor wirausaha secara menyeluruh. Selain itu keberhasilan dalam melakukan pemetaan juga bisa memberikan gambaran tentang persoalan dari setiap setting amatan yang muncul. Artinya, mereduksi dari semua persoalan sukses faktor tersebut adalah tantangan bagi kewirausahaan.

\section{METODE PENELITIAN}

Penelitian dilakukan menggunakan analisis SEM dengan responden yaitu pelaku wirausaha wanita di Solo. Pengumpulan data dilakukan dengan kuesioner yang diadopsi dari hasil sejumlah penelitian sebelumnya menggunakan 5 skala likert. Responden yang dipilih berdasarkan kriteria wirausaha wanita sukses dengan indikator yaitu kontinuitas usahanya minimal 5 tahun sejak didirikan.

\section{Variabel, Model dan Hipotesa}

Variabel penelitian dan indikator diadopsi dari sejumlah penelitian sebelumnya sebagai rujukan dalam pengembangan hipotesa. Identifikasi dari variabel dan indikator serta model penelitian terlihat pada tabel dan gambar berikut: 
Tabel 1. Indikator dan variabel penelitian

\begin{tabular}{|c|c|c|c|}
\hline No. & Variabel & Indikator & Sumber \\
\hline 1. & $\begin{array}{l}\text { Faktor Mikro } \\
\text { (Micro Factors) }\end{array}$ & $\begin{array}{ll}\text { - } & \text { Identifikasi peluang yang terbuka } \\
\text { - } & \text { Motivasi mencari tantangan baru } \\
\text { - } & \text { Komitmen terhadap kebebasan finansial } \\
\text { - } & \text { Eksistensi diri dan status sosial }\end{array}$ & $\begin{array}{l}\text { Jamali, (2009) } \\
\text { Perwej, (2012) }\end{array}$ \\
\hline 2. & $\begin{array}{l}\text { Faktor Makro } \\
\text { (Macro Factors) }\end{array}$ & $\begin{array}{l}\text { - Dukungan faktor lingkungan } \\
\text { - Dukungan faktor religi } \\
\text { - Dukungan faktor budaya } \\
\text { - Dukungan legitimasi wirausaha } \\
\text { - Dukungan faktor ekonomi } \\
\text { Dukungan faktor keluarga }\end{array}$ & Jamali, (2009) \\
\hline 3. & $\begin{array}{l}\text { Faktor } \\
\text { Kapabilitas } \\
\text { (Capabilities } \\
\text { Factors) }\end{array}$ & $\begin{array}{l}\text { - } \text { Inovasi } \\
\text { - } \text { Adaptasi } \\
\text { - } \text { Inteaktif } \\
\text { - Akses jejaring } \\
\text { - Perencanaan jangka panjang }\end{array}$ & $\begin{array}{l}\text { Durán-Encalada, } \\
\text { et al., (2012) }\end{array}$ \\
\hline 4. & $\begin{array}{l}\text { Faktor } \\
\text { Nilai Kerja } \\
\text { (Work Values } \\
\text { Factor) }\end{array}$ & $\begin{array}{l}\text { - Sikap positif terkait keterbukaan } \\
\text { - Sikap positif terhadap risiko } \\
\text { - } \quad \text { Sikap positif terhadap perubahan } \\
\text { - Sikap positif terhadap persaingan } \\
\text { - Sikap positif terhadap pengambilan keputusan }\end{array}$ & $\begin{array}{l}\text { Hirschi dan } \\
\text { Fischer, (2013) }\end{array}$ \\
\hline 5. & $\begin{array}{l}\text { Sukses Faktor } \\
\text { (Success } \\
\text { Factor) }\end{array}$ & $\begin{array}{l}\text { - } \text { Aset meningkat } \\
\text { - } \quad \text { Produksi meningkat } \\
\text { - } \quad \text { Juduktivitas meningkat } \\
\text { - } \quad \text { Profit meningkat }\end{array}$ & $\begin{array}{l}\text { Murphy, et al., } \\
\text { (1996) }\end{array}$ \\
\hline
\end{tabular}

Hasil kajian literatur menunjukan bahwa faktor mikro dan makro berpengaruh terhadap faktor nilai kerja (Jamali, 2009; Perwej, 2012). Hal ini menegaskan bahwa peran dari kedua faktor tersebut sangat penting dalam mendukung nilai kerja wirausaha wanita, terutama untuk kasus di negara berkembang. Oleh karena itu, kontribusi kedua faktor tersebut yaitu meningkatkan sikap positif pelaku wirausaha (Hirschi dan Fischer, 2013). Di sisi lain pengaruh sikap positif tersebut terhadap komitmen dan optimisme kewirausahaan adalah positif sehingga memacu sukses faktor kewairausahaan.

Temuan lainnya yang juga menarik bahwa faktor mikro dan makro berpengaruh terhadap faktor kapabilitas (Durán-Encalada, et al., 2012; Jamali, 2009; Perwej, 2012). Hal ini menunjukan bahwa interaksi antara nilai kerja dan kapabilitas menjadi faktor penting dalam mendukung sukses faktor (Murphy, et al., 1996). Oleh karena itu sukses faktor wirausaha ditentukan oleh beragam faktor yang masing-masing berinteraksi dari berbagai aspek yang terkait. Fakta ini secara tidak langsung menegaskan bahwa kajian tentang sukses faktor wirausaha bisa dilakukan dengan berbagai pendekatan mengacu setting amatan sesuai persoalan yang berkembang. Identifikasi dari sejumlah interaksi faktor yang mendukung sukses wirausaha sesuai setting amatan penelitian ini maka model penelitian yang dibangun dan hipotesa yang diajukan adalah sebagai berikut: 


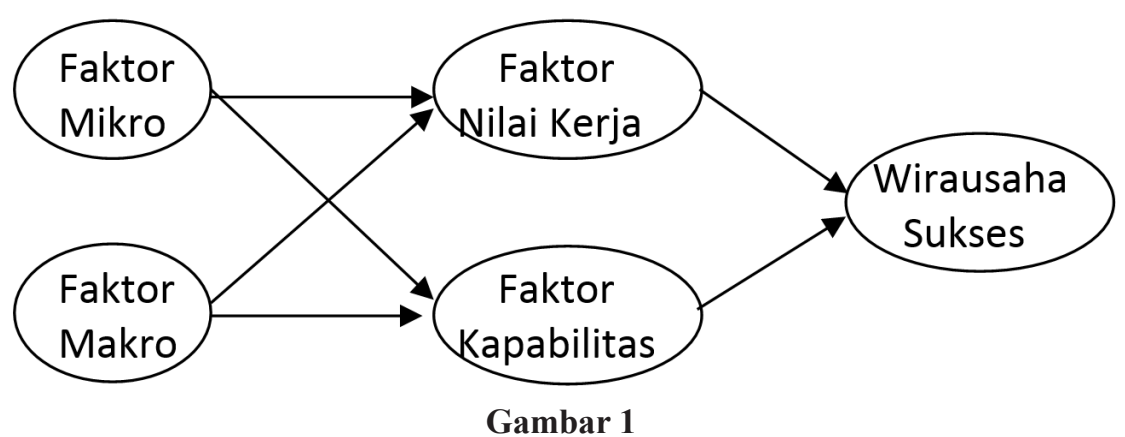

Dari model diatas, penelitian mengajukan sejumlah hipotesa untuk menjawab sukses faktor wirausaha wanita yaitu :

$$
\begin{aligned}
& \mathrm{H}_{1}=\begin{array}{l}
\text { Faktor mikro berpengaruh positif terhadap } \\
\text { faktor nilai kerja }
\end{array} \\
& \mathrm{H}_{2}=\begin{array}{l}
\text { Faktor mikro berpengaruh positif terhadap } \\
\text { faktor kapabilitas }
\end{array} \\
& \mathrm{H}_{3}=\begin{array}{l}
\text { Faktor makro berpengaruh positif } \\
\text { terhadap faktor nilai kerja }
\end{array} \\
& \mathrm{H}_{4}=\begin{array}{l}
\text { Faktor makro berpengaruh positif } \\
\text { terhadap faktor kapabilitas }
\end{array} \\
& \mathrm{H}_{5}=\begin{array}{l}
\text { Faktor nilai kerja berpengaruh positif } \\
\text { terhadap wirausaha sukses }
\end{array} \\
& \mathrm{H}_{6}=\begin{array}{l}
\text { Faktor kapabilitas berpengaruh positif } \\
\text { terhadap wirausaha sukses }
\end{array}
\end{aligned}
$$

\section{HASIL DAN PEMBAHASAN}

\section{Profil Responden}

Kuesioner yang disebar kepada responden mencapai 250 namun yang kembali dan bisa diolah mencapai 231 buah. Dari jumlah tersebut mayoritas berusia kurang dari 30 tahun (56 persen). Perbedaaan profil responden antara yang sudah menikah belum menikah yaitu 48 persen dan 52 persen. Data jumlah tanggungan anak ternyata masih banyak yang belum memiliki anak dan hal ini didukung fakta mayoritas masih berusia kurang dari 30 tahun. Fakta lain yang juga menarik adalah rentang waktu usaha kurang dari 5 tahun dengan dominasi lokasi usaha adalah tempat milik sendiri. Data responden menunjukan sebaran jenis usaha cenderung merata yaitu mulai dari jasa - perdagangan 70 orang (30 persen), warung makan - kuliner 45 orang (19 persen), bisnis online 30 orang (13 persen), pakaian - tekstil 29 orang (13 persen), jual pulsa 22 orang ( 9 persen), kelontong 18 (8 persen), bisnis multi level marketing 10
(4 persen), dan bisnis mebel 7 orang atau 3 persen.

\section{Uji Validitas dan Reliabilitas}

Hasil uji validitas dengan analisis faktor menunjukan pada tahap pertama ada 4 item yang dikeluarkan dari model yaitu FI1, FI4, FA5, dan FK6 sedangkan pada analisis tahap kedua hanya ada satu item yang dikeluarkan dari model yaitu FA4. Dari pengujian reliabilitas menunjukan bahwa semua variabel adalah reliabel sesuai rekomendasi yaitu nilai koefisien Cronbah's alpha lebih dari 0,6 (Nunnally, 1978).

\section{Asumsi SEM}

Pemenuhan asumsi yang mendasari penggunaan metode SEM dalam penelitian ini menunjukan untuk asumsi kecukupan sampel terpenuhi yaitu penggunaan Maximum Likelihood (Ghozali, 2008), asumsi normalitas menunjukan bahwa secara univariate dan multivariate, data penelitian ini tidak termasuk normal karena nilai critical ratio kurtosis diatas 2,58 (Ghozali dan Fuad, 2005). Persoalan normalitas untuk data primer relatif sulit dicapai karena terkait persepsian individu sehingga persoalan normalitas ini bisa diabaikan untuk kasus data primer (ibid, 2005). Terkait asumsi outlier bahwa dari jumlah indikator penelitian 22 sehingga nilai $\chi^{2}(22 ; 0.001)$ yaitu 48,3 dan hasil analisis menunjukan ada 7 outlier (responden no 24, $40,171,188,212,217,222)$, tetapi karena semua indikator dari penelitian ini dianggap penting maka tidak dikeluarkan dari model.

\section{Analisis Goodness of Fit Model}

Hasil pengujian dengan AMOS 18 menunjukan hasil goodness of fit model dari penelitian ini yaitu nilai $\chi^{2}=356.084$ dengan $\mathrm{df}$ 
$=203$ dan probabilitylevel $(p)=0,000$ atau lebih kecil dari 0,05 sehingga hal ini menunjukan matrik kovarian sampel berbeda dengan matrik kovarian estimasi yang berarti model tidak fit dengan data yang ada. Nilai CMIN/ $\mathrm{DF}=1,754$ sehingga ini mengindikasikan bahwa model fit, baik mengacu nilai batasan dari Wheaton ataupun Byrne. Nilai GFI = 0,874 atau kurang dari rekomendasi yaitu 0,9 sehingga data disebut tidak fit. Hasil analisis yaitu RMSEA $=0,057$ dan hal ini mengindikasikan model fit memenuhi batas minimal yaitu kurang dari 0,8 . Analisis nilai $\mathrm{AGFI}=0,842$ dan ini menunjukan tidak sesuai yang direkomendasikan yaitu lebih dari 0,9 sehingga data tidak fit. Begitu juga untuk hasil analisis TLI $(0,874)$ dan CFI $(0,889)$ sehingga data tidak fit. Oleh karena, uji goodness of fit model dapat disimpulkan secara keseluruhan model penelitian ini tidak fit seperti terlihat pada tabel sebagai berikut:

Tabel 2. Hasil uji goodness of fit model

\begin{tabular}{lccc}
\hline Kriteria & Hasil & Cut Off & Ket \\
\hline $\begin{array}{l}\chi^{2} \text { chi } \\
\text { square }\end{array}$ & 356.084 & Kecil & \\
$\begin{array}{l}\chi^{2} \text { sig. } \\
\text { probly }\end{array}$ & 0.000 & $\geq 0,05$ & Tidak Fit \\
CMIN/ & 1.754 & $\leq 2,00$ & Fit \\
DF & 0.874 & $\geq 0,90$ & Tidak Fit \\
GFI & $\leq 0,80$ & Fit \\
RMSEA & 0.057 & Kecil & Fit \\
RMR & 0.034 & $\geq 0,90$ & Tidak Fit \\
AGFI & 0.842 & $\geq 0,90$ & Tidak Fit \\
TLI & 0.874 & $\geq 0,90$ & Tidak Fit \\
CFI & 0.889 & & \\
\hline
\end{tabular}

\section{Uji Hipotesis}

Penelitian ini mengajukan 6 hipotesa mengacu setting amatan kewirausahaan di Solo. Hasil analisis secara lengkap terlihat pada tabel 3 .

Pengujian $\mathrm{H}_{1}$ menunjukan bahwa faktor mikro berpengaruh signifikan positif terhadap faktor nilai kinerja sehingga ini menguatkan asumsi pentingnya faktor mikro terhadap sukses faktor wirausaha yang dijabarkan melalui faktor nilai kinerja (Jamali, 2009; Perwej, 2012). Hasil pengujian tersebut juga identik dengan hasil pengujian $\mathrm{H}_{2}$ sehingga dapat dijelaskan peran penting dari faktor mikro terhadap faktor nilai kinerja dan faktor kapabilitas. Oleh karena itu hasil ini menjadi acuan identifikasi faktor mikro terhadap peluang pengembangan sukses faktor wirausaha melalui faktor nilai kinerja dan faktor kapabilitas.

Pengujian $\mathrm{H}_{3}$ menunjukan bahwa faktor makro berpengaruh signifikan positif terhadap faktor nilai kinerja, begitu juga dari temuan pengujian $\mathrm{H}_{4}$ bahwa faktor makro berpengaruh signifikan positif terhadap faktor kapabilitas. Hasil ini menegaskan bahwa peran faktor mikro dan makro tidak hanya memberikan pengaruh terhadap faktor nilai kinerja tapi juga faktor kapabilitas (ibid, 2009 dan 2012). Oleh karena itu, identifikasi terhadap faktor mikro dan makro menjadi penting dalam kaitan untuk memacu sukses faktor wirausaha sesuai setting amatan dalam penelitian ini. Identifikasi kedua faktor ini menjadi acuan terhadap sukses faktor wirausaha sehingga interaksi kedua faktor ini adalah penting (Durán-Encalada, et al., 2012; Jamali, 2009; Perwej, 2012).

Tabel 3. Hasil Uji Hipotesis

\begin{tabular}{ccccccc}
\hline Hipotesa & Variabel & Estimate & S.E. & C.R. & P & Keterangan \\
\hline $\mathrm{H}_{1}$ & FN <--- FI & .398 & .115 & 3.455 & $* * *$ & Signifikan \\
$\mathrm{H}_{2}$ & FK <--- FI & .473 & .149 & 3.183 & .001 & Signifikan \\
$\mathrm{H}_{3}$ & FN <--- FA & .393 & .098 & 4.013 & $* * *$ & Signifikan \\
$\mathrm{H}_{4}$ & FK <--- FA & .340 & .118 & 2.882 & .004 & Signifikan \\
$\mathrm{H}_{5}$ & $\mathrm{SF}<---\mathrm{FN}$ & .411 & .090 & 4.578 & $* * *$ & Signifikan \\
$\mathrm{H}_{6}$ & $\mathrm{SF}<---\mathrm{FK}$ & .182 & .067 & 2.734 & .006 & Signifikan \\
\hline
\end{tabular}

Ket: signifikan pada $\alpha=1 \%$ 
Temuan lain yang tidak bisa diabaikan adalah hasil pengujian $\mathrm{H}_{5}$ bahwa faktor nilai kinerja berpengaruh signifikan positif terhadap sukses faktor wirausaha wanita. Hasil ini sejalan dengan hasil pengujian $\mathrm{H}_{6}$ sehingga dapat disimpulkan bahwa kedua faktor ini mendukung terhadap sukses faktor wirausaha (Murphy, et al., 1996). Di satu sisi temuan ini menjadi acuan terhadap peluang riset lanjutan terkait identifikasi sukses faktor wirausaha, dan di sisi lain temuan ini menjadi tantangan untuk memetakan nilai penting dari sukses faktor wirausaha wanita, terutama kasus di negara berkembang. Identifikasi pengujian hipotesa secara keseluruhan terlihat pada gambar sebagai berikut

\section{KESIMPULAN, KETERBATASAN DAN SARAN}

\section{Kesimpulan}

Sukses faktor wirausaha dipengaruhi oleh berbagai faktor sehingga identifikasi untuk setiap kasus memberikan gambaran yang berbeda. Hal ini mengindikasikan bahwa generalisasi hasil dari temuan ini mengacu setting amatan wirausaha wanita di Solo. Di satu sisi temuan ini memberikan pemahaman tentang peran penting dari faktor mikro, makro, nilai kinerja dan kapabilitas terhadap sukses faktor wirausaha, meski di sisi lain masih perlu eksplorasi terhadap faktor-faktor lain yang belum teridentifikasi dari hasil penelitian ini.

\section{Keterbatasan}

Data yang tidak fit dari temuan penelitian ini menjadi keterbatasan yang perlu dicermati lebih lanjut sesuai prosedur penelitian yang menggunakan model analisis SEM dan pembatasan terhadap wirausaha wanita juga perlu dicermati. Artinya meski prosedur penelitian ini telah dilakukan sesuai prosedur yang rigid, namun semua keterbatasan dari penelitian ini menjadi acuan untuk melakukan eksplorasi keberagaman faktor yang dapat mendukung sukses faktor wirausaha.

\section{Saran}

Identifikasi dari keterbatasan penelitian menjadi acuan untuk penelitian lanjutan sehingga pemetaan terhadap faktor-faktor yang mendukung sukses faktor wirausaha dapat dijabarkan secara lebih kompregensif.

\section{DAFTAR PUSTAKA}

Abu-Asbah, K.M. dan Heilbrunn, S. (2011). Patterns of entrepreneurship of Arab women in Israel. Journal of Enterprising Communities: People and Places in the Global Economy. 5 (3): 184-198.

Achmad, N. (2012). Model Edukasi Pengembangan Sikap Motivasi Wirausaha. Laporan Penelitian Kolaboratif. FEB UMS.

Achmad, N dan Saputro, E.P (2015). Model Sukses Faktor Wirausaha Wanita. Laporan Penelitian Hibah Bersaing. Dikti.

Alam, S.S., Senik, Z.C., dan Jani, M.F.M. (2012). An exploratory study of women entrepreneurs in Malaysia: Motivation and problems. Journal of Management Research. 4 (4): 282-297.

----- Jani, M.F.M., dan Omar, N.A. (2011). An empirical study of success factors of women entrepreneurs in southern region in Malaysia. International Journal of Economics and Finance. 3 (2): 166-175.

Al-Dajani, H. dan Marlow, S. (2013). Empowerment and entrepreneurship: A theoretical framework. International Journal of Entrepreneurial Behaviour \& Research. 19 (5): 503-524.

Aramand, M. (2013). Women entrepreneurship in Mongolia: The role of culture on entrepreneurial motivation. Equality, Diversity and Inclusion: An International Journal. 32 (1): 68-82.

Blackburn, R. dan Kovalainen, A. (2009). Researching small firms and entrepreneurship: Past, present and future. International Journal of Management Reviews. 11 (2): 127-148.

Canizares, S.M.C. dan Garcia, F.J.F. (2010). Gender differences in entrepreneurial 
attitudes. Equality, Diversity and Inclusion: An International Journal. 29 (8): 766-786.

Chong, W.Y. (2012). Critical success factors for small and medium enterprises: Perceptions of entrepreneurs in urban Malaysia. Journal of Business and Policy Research. 7 (4): 204-215.

Dawson, C. dan Henley, A. (2012). "Push" versus "pull" entrepreneurship: An ambiguous distinction? International Journal of Entrepreneurial Behaviour \& Research. 18 (6): 697-719.

Durán-Encalada, J.A., Martin-Reyna, J.M., dan Montiel-Campos, H. (2012). A research proposal to examine entrepreneurship in family business. Journal of Entrepreneurship, Management and Innovation, 8 (3): 58-77.

Forson, C. (2013). Contextualising migrant black business women's work-life balance experiences. International Journal of Entrepreneurial Behaviour \& Research. 19 (5): 460-477.

Gonzalez-Alvarez, N. dan Solis-Rodriguez, V. (2011). Discovery of entrepreneurial opportunities: A gender perspective. Industrial Management \& Data Systems. 111 (5): 755-775.

Hattab, H. (2012). Towards understanding female entrepreneurship in Middle Eastern and North African countries: A cross-country comparison of female entrepreneurship. Education, Business and Society: Contemporary Middle Eastern Issues. 5 (3): 171-186.

Hirschi, A. dan Fischer, S. (2013). Work values as predictors of entrepreneurial career intentions. Career Development International. 18 (3): 216-231.

Hoyos-Ruperto, M.D., Romaguera, J.M., Carlsson, B., dan Lyytinen, K. (2013). Networking: A critical success factor for entrepreneurship. American Journal of Management. 13(2): 55-72.
Ireland, R.D., Reutzel, C.R., dan Webb, J.W. (2005). Entrepreneurship research in AMJ: What has been published, and what might the future hold? Academy of Management Journal. 48 (4): 556-564.

Itani, H., Sidani, Y.M., dan Baalbaki, I. (2011). United Arab Emirates female entrepreneurs: Motivations and frustrations. Equality Diversity and Inclusion: An International Journal. 30 (5): 409-424.

Jamali,D.(2009). Constraints and opportunities facing women entrepreneurs in developing countries: A relational perspective. Gender in Management: An International Journal. 24 (4): 232-251.

Javadian, G. dan Singh, R.P.(2012). Examining successful Iranian women entrepreneurs: An exploratory study. Gender in Management: An International Journal. 27 (30): 148-164.

Kargwell, S.A. (2012). Women entrepreneurs breaking through: Push and pull within UAE cultural context. International Journal of Business and Social Science. 3 (17): 122-131.

Kumar, A. (2013). Women entrepreneurs in a masculine society: Inclusive strategy for sustainable outcomes. International Journal of Organizational Analysis. 21 (3): 373-384.

Kwong, C., Jones-Evans, D., dan Thompson, P. (2012). Differences in perceptions of access to finance between potential male and female entrepreneurs: Evidence from the UK. International Journal of Entrepreneurial Behaviour \& Research. 18 (1): 75-97.

Kyrgidou, L.P. dan Petridou, E. (2013). Developing women entrepreneurs' knowledge, skills and attitudes through e-mentoring support. Journal of Small Business and Enterprise Development. 20 (3): 548-566. 
Lee, L. dan Yang, C.L. (2013). Key success factors in female micro entrepreneurship :A study of the catering business. Service Science and Management Research (SSMR). 2 (3): 39-47.

Marlow, S. dan McAdam, M. (2013). Gender and entrepreneurship: Advancing debate and challenging myths; exploring the mystery of the under-performing female entrepreneur. International Journal of Entrepreneurial Behaviour \& Research. 19 (1): 114-124.

Murphy, G. B., Trailer, J. W., dan Hill, R. C. (1996). Measuring performance in entrepreneurship research. Journal of Business Research, 36 (1): 15-23.

Nawaz, F. (2009). Critical Factors of Women Entrepreneurship Development in Rural Bangladesh. Bangladesh Development Research Working Paper Series. Bangladesh Development Research Center (BDRC)

Pathak, S., Goltz, S., dan Buche, M.W. (2013). Influences of gendered institutions on women's entry into entrepreneurship. International Journal of Entrepreneurial Behaviour \& Research. 19 (5): 478-502.

Patterson, N., Mavin, S., dan Turner, J. (2012). Envisioning female entrepreneur: Leaders anew from a gender perspective. Gender in Management: An International Journal. 27 (6): 395-416.

Perwej, A. (2012). The women adoption in owned businesses and entrepreneurship in India. International Journal of Emerging Trends \& Technology in Computer Science (IJETTCS). 1 (4): 5661.

Pines, A.M., Lerner, M., dan Schwartz, D. (2010). Gender differences in entrepreneurship: Equality, diversity and inclusion in times of global crisis. Equality, Diversity and Inclusion: An International Journal. 29 (2): 186-198.
Rao, V., Venkatachalm, A., dan Joshi, H.G. (2013). A study on entrepreneurial characteristics and success of women entrepreneurs operating fashion and apparel business. Asian Journal of Management Sciences and Education. 2 (2): 136-147.

Raposo, M. dan do Paço, A. (2011). Entrepreneurship education: Relationship between education and entrepreneurial activity. Psicothema. 23 (3): 453-457.

Robichaud, Y., Cachon, J.C., dan Haq, R. (2010). Motives, success factors, and barriers among Canadian female entrepreneurs: The Case of Greater Sudbury. Entrepreneurial Practice Review. 1 (2): 36-65

Rauch, A., dan Frese, M. (2000). Psychological approaches to entrepreneurial success. A general model and an overview of findings. In C.L. Cooper \& I.T. Robertson (Eds.), International Review of Industrial and Organizational Psychology (pp. 101-142). Chichester: Wiley.

Sánchez, J.C dan Gutiérrez, A. (2011). Entrepreneurship research in Spain: Developments and distinctiveness. Psicothema. 23 (3): 458-463.

Short, J.C., Moss, T.W., dan Lumpkin, G.T. (2009). Research in social entrepreneurship: Past contributions and future opportunities. Strategic Rntrepreneurship Journal. 3: 161-194.

Simpeh, K.N. (2011). Entrepreneurship theories and empirical research: A summary review of the literature. European Journal of Business and Management. 3 (6): 1-8.

Siringi, E.M. (2011). Women's small and medium enterprises for poverty alleviation in Sub-Saharan Africa: Lessons from Kenya. Management Research Review. 34 (2): 186-206. 
Sullivan, D.M. dan Meek, W.R. (2012). Gender and entrepreneurship: A review and process model. Journal of Managerial Psychology. 27 (5): 428-458.

Vadnjal, J., dan Vadnjal, M. (2013). The role of husbands: Support or barrier to women's entrepreneurial start-ups? African Journal of Business Management. 7(36): 3730-3738.

van Gelderen, M., Brand, M., van Praag, M., Bodewes, W., Poutsma, E., dan van Gils, A. (2008). Explaining entrepreneurial intentions by means of the Theory of Planned Behaviour. Career Development International. 13 (6): 538-559.

Veciana, J.M. dan Urbano, D. (2008). The institutional approach to entrepreneurship research: Introduction. International Entrepreneurship Management Journal. 4: 365-379.

Zhu. L. dan Chu, H.M. (2010). Motivations, success factors and problems encountered by Chinese women entrepreneurs: A factor analysis. International Review of Business Research Papers. 6 (5): 164180.

Zulkifli, R.M. dan Rosli, Z.M. (2013). Entrepreneurial orientation and business success of Malay entrepreneurs: Religiosity as moderator. International Journal of Humanities and Social Science. 3 (10): 264-275. 